\title{
A psychoanalytic view of sleep
}

\author{
Malcolm Pines \\ M.B., F.R.C.P., F.R.C.Psych., D.P.M.
}

Maudsley Hospital

\begin{abstract}
Summary
The basic psychoanalytic contributions to theories of sleep, awakening, falling asleep and the sleep wakefulness continuum are briefly discussed. Some clinical material illustrates the psychopathology underlying sleep occurring during the psychoanalytic session.
\end{abstract}

In the psychoanalytic situation the patient lies down and is asked to 'free associate' in a state of 'quiet and reflecting self observation'. Around this nuclear, strictly defined norm radiate states of consciousness of all degrees of awakeness and sleepiness. There are insensible transitions towards reveries and dreams in one direction and in the other direction towards directed, secondary processed structured mental work (Lewin, 1955). The analyst therefore has many opportunities to follow changes in the level of consciousness of his patients from that of elated hypomanic sleeplessness to gradual or sudden onset of sleep during the session; to follow the development or resolution of insomnia and to study the mental activity during sleep as revealed during dreams. He is in a position to confirm what Lawrence Kubie (1949) pointed out: 'We are never either totally awake or totally asleep. These are relative and not absolute terms. Parts of us are asleep in our waking moments and awake in our sleeping moments and in between lie all gradations of states of activity and inactivity; investigation and pursuit; assertion, aggression and destruction or defence withdrawal and fight or silence, inactivity, dreaming and sleep.'

Psychoanalytic views on sleep are in many cases derived from clinical observations and theoretical reconstructions before EEG studies (Proceedings, 1942) and there are those who articulate with these modern studies (Fisher, 1965; Meissner, 1968; Hawkins, 1970; Zetzel, 1970; Hartmann, 1973).

We begin with Freud's dramatic plunge into the world of dreams and sleep, with his 'Interpretation of Dreams' (Freud, 1900). Note that Freud studied dreams more than he studied sleep but what he had to say about sleep is important and set the framework for most subsequent work. He asserted that sleep is an active not a passive process, that we wish to sleep and therefore actively withdraw our atten- $\omega$ tion from the external world. 'We are not in the habito of devoting much thought to the fact that every night 3 human beings lay aside the wrappings in which they of have enveloped their skin as well as anything they? may use as a supplement to their bodily organ, for $D_{\mathcal{E}}$ instance, their spectacles, their false hair and teeth $\dot{\sim}$ and so on. We may add that when they go to sleep? they carry out an entirely analogous undressing of $\frac{}{D}$ their minds and lay aside most of their psychical $\vec{c}$ acquisitions. Thus on both counts they approach remarkably close to the situation in which they began $\frac{c}{d}$ life. Somatically, sleep is a re-activation of intrauterine existence fulfilling as it does the conditions of $\overrightarrow{0}$ repose, warmth and exclusion of stimulus; indeed, 這 sleep many people resume the fetal posture. T psychical state of a sleeping person is characterized by an almost complete withdrawal from the surrounding world and cessation of all interest in it' (Freud, 1925). 'A dream tells us that something was $\frac{}{\varnothing}$ going on which tended to interrupt sleep and enables $\varrho$ us to understand in what way it has been possible to $\overrightarrow{\overrightarrow{0}}$ fend off the interruption. The final outcome is that 3 the sleeper has dreamt and is able to go on sleeping; the internal demand which was striving to occupy him has been replaced by an external experience $\frac{}{5}$ whose demand has been disposed of. A dream is therefore amongst other things a projection; an 3 externalization of an internal process.'

Let me define some of the terms we are going to $\frac{\rho}{3}$ encounter repeatedly that make up the psychoanalytical conceptual shorthand with which we 의 handle complex psychological phenomena. Ego is $\frac{?}{0}$ the name given to that collectivity of mental functions that mediate the person's relationship both to the N external world and to the internal world of vital $N$ drives and unconscious mental forces and processes; $N$ the phenomenon of consciousness is a function of the $\omega$ system. Between the conscious and the unconscious systems lies the pre-conscious, containing images and $\stackrel{\circ}{\subset}$ ideas which are latent, ready to emerge, already $\Phi_{\overparen{D}}$ partly screened and prevented from flooding con- $\cdot$ sciousness by a process of selective attention and ${ }^{\circ}$ inattention. The superego is the name given to the $\underset{\mathbb{D}}{\mathbb{D}}$ 
area of the personality where social relations have entered most noticeably into the nature of the person through his acceptance of the standards and practices of his early environment. The asocial, helpless, dependent infant has, in a few brief years, to become a person with a unique, recognizable personality, able to move away from the family of origin and prepared to lead a self-regulated relatively independent existence. You will hear me use the word cathexis, a term for the investment of the mental function with a hypothetical charge of energy that can fluctuate quantitatively. Cathexis can be attached or withdrawn from a part of the body schema or from part of the mental apparatus. Withdrawal can be voluntary or involuntary; in the latter case it is likely to be caused by mental conflict, classically as in a sensory anaesthesia or in motor paralysis. The term ego feeling will be explained later. As already stated, Freud saw sleep as a regressive state, a reversion to early states of being, and spoke of a dream as a guardian of sleep. Impressions of the day before, day residues, become linked up during sleep with the drives that constantly press for discharge into consciousness, basically sexual and aggressive drives. The state of sleep allows the psychic representatives of these drives to emerge as wishes and impulses. Censorship is reduced by the state of sleep but is not lost and the dream represents the acceptable compromise between the primitive drive and the requirements of conscience and the censor. The result of this 'dream work' is the dream. Already in 1900 Freud understood that the dream represents a wakening of the sleeper, hence the dictum that the dream is the guardian of sleep. This dictum should now be reversed as EEG studies show that REM periods are the necessary background for dreaming; sleep, therefore, is the guardian of the dream. He emphasized the motor paralysis that accompanies the dream state so that the dreamer has no access to motility and therefore is safe from carrying out forbidden actions. Withdrawal of attention from the external world brings about a greater exposure to the inner world of bodily and mental stimuli. The end result is not action but perception; in the waking state perception leads to action.

The mental state in sleep: the dream ego. Federn (1953) has given us most sensitive and acute insights into this, for which we need to use his terminology. His term ego feeling defines 'a feeling of bodily and mental relation in respect to time and content', and is related to the continuity in time, space and causality of the person. It is subjective experience of many ego functions synthesized into a feeling of unity. Many waking and going to sleep experiences can be differentiated by applying Federn's concepts. He discriminated between a 'mental' ego and a 'body' ego feeling. The body ego is a compound feeling that includes all motor and sensory memories concerning one's own person, united into a characteristic feeling experience. The mental ego is an inner mental experience from which, by conversion, processes can be projected either into the body as in conversion hysteria or outside the body into the external world as in psychosis.

As we gradually fall asleep both ego feelings undergo modifications. Pleasurable fantasies replace dull workaday reality and our attention falls upon the body which is experienced as changing in many ways, altering in its dimensions, its movements and most particularly its boundaries. Those 'frontier zones' of the body, that is those parts of the body and the environment immediately about it, begin to blur and to fuse. Processes taking place within the body are experienced now as taking place in the outside world. All this time a certain type of heightened self observation is taking place. A mental ego thus is still active, functioning, nearer to the waking level than does the body ego, though the body ego can quickly revert to its usual level of function if the body is moved or if the person wills it so. Normally sleep supervenes fairly smoothly with the loss of waking consciousness but a partial form of consciousness is restored in the dream state where now a 'dream ego' can be recognized that differs in certain ways from the waking ego.

Under certain conditions this smooth onset of sleep does not occur. Probably we all remember how, as children, lying hot and sick in bed, the wallpaper begins to approach and to recede, we feel giddy as if sinking or floating, sometimes feeling sick, though sometimes this has a pleasant feeling to it. The mouth, hands and skin all feel different, there is a doughy, crumbly feeling of fullness in the mouth, which is strange and unusual. Paying attention to these phenomena does not make them disappear, thinking of them afterwards will often vividly recall the sensations. The rhythm of near and far, larger and smaller, continues until we fall asleep. The acute observer of these phenomena, Otto Isakower (1938), whose name has been given to this state, pointed out its affinity with auras and déjà $v u$, where a similar intensified self observation and preservation of a certain distance from the experience, which is not regarded as entirely real, pertain. He suggested that an 'estrangement' takes place between two parts of the ego, the body ego and the mental 'perceptual' ego; the latter remains more awake and observes how the other has already regressed a long way back to a perceptual experience organized under the influence of an early 'mouth dominated' experience like that of a suckling babe that is falling asleep at the breast. This breast fluctuates in experienced size as the infant loses grasp of consciousness. Attention is withdrawn from outside to inside, the distinction 
between what is me and what is not me, which exists only in a rudimentary form in a small baby, is progressively lost. The child or adult is in fact hallucinating an experience 'as if I have the breast' and thereby regains in comforting fantasy what has in fact been lost, yet which remains for us the prime symbol of comfort. Later, Bertram Lewin (1946, 1948,1950 ), writing of the process of sleep onset of the suckling babe, described a merger with the breast where the experience is of sinking into it, as it were being 'swallowed up' in a pleasurable manner; alternatively the babe may imagine himself to have internalized nipple and breast or bottle, his source of bliss, and is falling asleep as it were in total possession of what to us as observers is external and part of mother but which to him is entirely his and part of him. According to Lewin's very acute dream observations the visual perception of the flattened breast surface which is the last waking impression of the babe is taken into his perceptual world. It flattens out and becomes the 'screen' upon which are projected his dream images. (Just so does the pampered passenger waft through the air on a celestial jumbo, watching on a screen whatever we project on to it of our own adult synthetic dreams.) In some dreams this very screen is seen blank, or we may suddenly see this dream screen rolling up and disappearing. It may appear as a gelatinous film or as a blank page or record. Lewin suggested that the screen is the mental representative of the wish to sleep and to remain asleep. The dream stimuli, which are in fact the 'awakeners', appear on the screen as the dream images. Above a certain intensity of stimulation the dreamer will awaken, particularly if the person's body is experienced with marked definition and strength in his outlines and actions during the dream. It is as if the body ego, normally dormant and almost nonexistent in dreams, has been re-awakened, recathected, vested with psychic energy and with this drive to motility the sleeper awakens. Thus, the dream ego is closer to the mental ego than the body ego. Body contours in dreams are usually less complete, if they are represented at all. Although in dreams we meet well defined other persons there is no feeling of strangeness attached to the fact that we lack clear definition ourselves (Federn, 1953). Studies of wakening (Federn, 1953; Grotjahn, 1942; Isakower, 1954; Grand and Pardes, 1974) show that these different ego functions can recover sequentially: first we regain contact with and recognition of our bodies, the stranger in the bed becomes myself and is linked up with the sense of my mental existence and continuity with myself: I look to see where did I put my watch, my glasses, to see what time it is, perhaps to see who that is who shares my bed. Thus first we regain possession of the body ego, then of the mental ego and its functions of cognition, of awareness of the presence of both internal and external reality; then we proceed to integrate these dual aspects of a single reality and finally become aware of conflicting $\stackrel{\varrho}{c}$ needs, for instance whether to go on sleeping or to arise. Having mastered this exquisite and tormenting $\stackrel{\vec{T}}{\rightarrow}$ choice I rise triumphant, displaying the highest levels $\frac{}{2}$ of will power of the day, reassuming the mantle of $\bar{\sigma}$. self (though sometimes I wonder if a greater display $\frac{\bar{c}}{\vec{D}}$ of will would be to stay in bed rather than to arise, $\stackrel{\varnothing}{\Omega}$ mere slave to destiny).

Before EEG studies confirmed it, many analysts were aware of a sleeping-waking cycle at night. Jekels (1945) pointed out, following Freud, that we know the dreamer as one who is awake in sleep, who is active in this phase of sleep and that the whole 8 state of sleep is one of differing levels of activities, 3 from active withdrawal to active awakening. He in emphasized that sleep represents a threat to the unity and continuity of the personality and that we are $\stackrel{\omega}{\omega}$ threatened by a loss of self in sleep. In analytic i terminology the ego partly merges with the id, 0 returning whence it came. To our waking selves there is something here of the threat of death, loss of differentiation and loss of self. Just as the schizophrenic patient will feel that the world is dying when in reality it is his own ego that is becoming threatened and weakened by withdrawal of energy or by eruptio $\vec{\theta}$ from the layers of the unconscious mind, so doe oे sleep threaten us with death. 'Sleep, the death of eack. day's life' (Macbeth: Shakespeare). The Greeks gav to Hermes a dual aspect, that of bringer of sleep and dreams and that of the chthonic god, the bringer of death (Death and his Brother Sleep: Shelley). Wakening is a restitution of the ego and a return to life. Even in sleep we awaken periodically to reassert our 'selves'. Jekels suggests that it is through this process of constant wakening in sleep that our 'collapsed' egos contact the images of others during dreams and prepare us thereby to reassert our claim on life so that by morning we may return to life thoroughly equipped with both will power and a readiness for action. In terms of our poetic psychoanalytical theory of instincts, the life instincts and death instincts hold alternate sway during sleep and once only does the victory pass to the latter.

The sleep awakedness boundary establishes for the infant its early sense of the reality of the external world and differentiates it from hallucination and dream. The external world provides real gratifications and frustrations. This process is valvular (Lewin, 1949): the external world penetrates deep into the sleep world, but the opposite process of emergence of the sleep world into the waking world is prevented by some mental mechanisms. Should these break down we see the major waking dream of schizophrenia or the minor waking dreams of disturbed ideation and effects; sometimes states of 
depersonalization or of frustration and rage which a patient will bring to a session later can be traced to the aftermath of a dream. Such dream effects penetrate into the waking world more easily during states of pre-menstrual tension. Lewin has reported on manic patients whose manic behaviour seems to represent a repressed dream content that follows on a 'blank' dream. Strange though it may seem, there are some powerful resemblances between the manic state and the dream state in that in both there is a loss of mental structure. In the dream the ego and the id merge; in the manic state it is the ego and superego that lose their differentiation and thereby the patient feels that all bounty is rightfully his and no restraint need exist. This resembles the wish fulfilment dreams of the small child. Thus the manic patient is living a pathological wish fulfilment dream full of denial of pain and loss. Similarly a state of elation may follow sleep of the 'benign stupor' state which itself may follow a consciously or dream experienced wish to be dead.

Dreams that reveal frank primitive wishes of incest or of murder may lead to 'vast careers' of denial leading eventually to drug-induced stupors or to hypomania. The fear of sleep leads to a pathological sleep substitute for it is self-induced, that is a selfinduced magically controlled sleep state through the use of drugs or alcohol.

Disturbed sleep. Sleep as a reaction to and escape from emotional stress can be observed directly in psychoanalytic sessions. The shift to the sleep end of the continuum of sleep wakefulness can be studied directly, and observations have been reported from early in the history of psychoanalysis (Ferenczi, 1914; Davison, 1945; Stone, 1947). There is general agreement that sleep appears as a defence against the threat of emergence of frightening impulses and fantasies, often of destructive rage or of sexual submission, that consciousness is lost and motility abandoned as a safeguard against conscious awareness and the actual danger of impulsive action. Some authors maintain that this withdrawal state represents a hypnosis-like phenomenon rather than a true sleep state, though it may pass into sleep proper (Fliess, 1953; Dickes, 1965; Silber, 1970).

A patient of mine frequently lost consciousness in her sessions over a period of many months. She was constantly threatened by outbursts of rage, which occurred most frequently towards the end of sessions. She would fall 'asleep' when she was still lying on the couch or else sleep supervened with narcoleptic-like suddenness during the move from couch to door. The 'sleep' was profound and rousing was often difficult. On some occasions when I had to leave her and returned an hour or two later she would still be lying motionless in the same position as she had fallen. Sometimes the rigidity of the body resembled a catatonic state indicating the enormous tension struggle not to give way to outbursts of destructive rage. On some occasions this defence failed and she was driven to attack me physically. This patient also clearly showed that extinction of consciousness occurs when, in fantasy, all life is destroyed, both in inner and outer worlds. She had a very great fear of lying on the couch and allowing herself access, via introspection, to the contents of the mind. For months at a time she had to sit tensely in an armchair clinging tightly to it with indrawn legs as if to attain some degree of security in limited space; the unbounded space of the couch with its invitation to relaxation of tight control of mental processes threatened loss of control of ego boundaries that had to be maintained by a constant state of arousal and by paranoid scrutiny of the environment. Once on moving back to the couch after months in the chair she recited a horrifying caricature of a 'listen with mother' story in which the children listening to the story were all slaughtered, thrown out of the window with their brains splashing on to the pavement below; then their mothers too were slaughtered, then their fathers, then the radio speakers, followed by the whole population of the world and finally even God died; at that point when her world was emptied of all other persons and the overwhelming destructive rage threatened 'ego-extinction', to destroy the last vestiges of self she fell into a deep slumber.

The same patient also demonstrated vividly to me a soundly established analytic finding, that sleep withdrawal is a defence against a regression to an infantile state of fascinated arousal with terrifying fantasies of parental sexual intercourse, the 'primal scene'. First described by Freud in the 'Wolf Man' case history (Freud, 1918) this finding has received frequent confirmation. The reconstruction is that the infant is awakened by the sound and sometimes by the sight of parental intercourse, but the infant construes this as a savage and frightening assault by one parent upon the other, frequently as a castration and that the infant, highly aroused by this stimulation, attempts to resort to sleep as a defence, although the sleep may now be disturbed by dreams or nightmares in which the psychic stimulation continues, but to some extent now bound by the dreamwork. Isakower (1938) suggested, and Fink (1967) confirmed, that the so-called Isakower phenomenon often appears as a defence against the emergence of primal scene material and that a regression to the security of the hallucinated maternal breast is sought for as a reassurance. The wish to stay asleep so as not to witness coitus is often paralleled in the session by the patient's unwillingness to 'see' what is becoming clear in the analytic material. In my patient's analysis, episodes have occurred where following dreams and fantasies have made it abundantly clear that she 
was beginning to experience the most intense jealous rage towards her parents, and towards me, in the transference for their ability to produce babies and that this jealousy led to painful, now conscious fantasies of destroying infants and myself through smashing heads in. This became acted out through paranoid tirades against me for failing to understand her which I experienced as having my mind hammered in. Reciprocally my voice and words were experienced by her as painful intolerable assauits upon her ears and upon her mind. Thus, though now in the waking state, the repressed, warded off fantasies were acted out without the patient recognizing what she was doing and avoiding contact with her painful past memories-'the return of the repressed'.

Sleep in the analytic session can also represent progressive moves. This was pointed out by Scott (1952). He observed that in some patients the regressive sleep state and the fantasies accompanying wakening in the session led to a deepening of the level of analysis and to fuller reconstructions of earlier infancy. He suggests asking the patient 'if you fell asleep how would you wish to be awakened?' The patient's wish gives some indication of the wish fulfilment fantasies that he has of waking to a world where pain is absent and satisfaction abundant and instant. He observed that the sleep in the session can be a defence against the recall of either a sleep dream or a day dream.

I believe that with the patient I have already cited, her capacity to fall asleep in a rage and then to be awakened by me, finding herself covered with a rug and offered care and concern helped to begin to form a nucleus of a sense of safety in a relationship that could survive her omnipotent rage and that without this our relationship could not have been established. She is not able to report anything but dream fragments on wakening, possibly because the level of sleep is too deep and the capacity for communication on wakening is scarcely available.

\section{Conclusions}

Psychoanalysts have contributed to the understanding of sleep by studying: (1) the psychoanalytic situation and its relationship to sleep; (2) the sleepwakefulness continuum and the sleep-wakefulness cycle; (3) the normal processes of falling asleep and of wakening; (4) the mental state of the sleeper and dreamer; (5) conditions that promote good sleep or induce bad sleep; (6) the relationship of sleep and psychosis; (7) the experimental study of dreaming and the place of dreaming in the economy of mental life; (8) the functions of sleep and dreaming in infantile maturational processes.
Some theories as to the basic nature of sleep and $\stackrel{2}{2}$ psychology have been derived from these studies, yet $\frac{\mathbb{Q}}{c}$ still sleep retains its ancient elusive magic.

\section{References}

Davison, C. (1945) Disturbances of sleep mechanism. Psychoanalytic Quarterly, 14, 478.

DiCKES, R. (1965) The defensive function of an altered state $\frac{\bar{\omega}}{\supset}$ of consciousness - a hypnoid state. Journal of the American $\stackrel{\square}{\triangle}$ Psychoanalytical Association, 13, 356.

FEDERN, P. (1953) Ego Psychology and Psychosis (Ed. by E. ڤ Weiss). Imago Publishing Co., London.

FERENCZI, S. (1914) On falling asleep during analysis. In: Further Contributions to the Theory and Technique of $\overrightarrow{1}$ Psychoanalysis. International Psychoanalytic Library, No. 11, London, Hogarth Press.

FINK, G. (1967) An analysis of the Isakower phenomenon. Journal of the American Psychoanalytical Association, 15, 281 .

FISHER, C. (1965) Psychoanalytic implications of recent research on sleep and dreaming. Journal of the American Psychoanalytical Association, 13, 2, 197.

FliEss, R. (1963) The hypnotic invasion: a clinical observation. Psychoanalytic Quarterly, 22, 497.

FREUD, S. (1900) The Interpretation of Dreams (Ed. by J. 옥 Strachey). Standard Edition, Vol. 4. Hogarth, London. Freud, S. (1925) A Metapsychological Supplement to the Theory of Dreams (Ed. by J. Strachey). Standard Edition, Vol. 19, 219. Hogarth, London.

Freud, S. (1918) From the History of an Infantile Neurosis. 류 Standard Edition, Vol. 17. Hogarth, London.

Grand, S. \& PARDES, H. (1974) The transition from sle\&̧ $\overrightarrow{0}$ to wakefulness: implications of the study of laboratoy dream reports for the psychoanalytic situation. Journal $\mathbb{E}$ the American Psychoanalytical Association, 22, 1, 58.

Grotjahn, M. (1942) The process of awakening. Psychoanalytic Review, 19, 1.

Hartmann, E. (1973) The Functions of Sleep. Yale University 음 Press.

Hawkins, P. (1970) Dream Research and Psychoanalytic $\stackrel{\mathbb{Q}}{\varrho}$ Theory in Sleep and Dreaming (Ed. by E. Hartmann). International Psychiatry Clinics, Series 7. Little, Brown, $\frac{0}{3}$ Boston.

ISAKOWER, O. (1938) A contribution to the psychopathology of phenomena associated with falling asleep. International. Journal of Psychoanalysis, 19, 331.

ISAKOWER, O. (1954) Spoken words and dreams. Psycho- 3 analytic Quarterly, 23, 1.

JEKELS, L. (1945) A bioanalytical contribution to the problem of sleep and wakefulness. Psychoanalytic Quarterly, 14, 169.

KUBIE, L. (1949) Instinct and homeostasis. In: The Yearbook 0 of Psychoanalysis, 5.

LEWIN, B, (1946) Sleep, the mouth and the dream screen. In : Selected Writings of Bertram D. Lewin (Ed. by J. Arlow). Psychoanalytic Quarterly Inc., New York.

LEWIN, B. (1948) Interferences from the dream screen. 을 In: Selected Writings of Bertram D. Lewin (Ed. by J. N Arlow). Psychoanalytic Quarterly Inc., New York. O LEwIN, B. (1950) Addenda to the theory of oral eroticism. $N$ In: Selected Writings of Bertram D. Lewin (Ed. by J.O Arlow). Psychoanalytic Quarterly Inc., New York.

LEWIN, B. (1949) Mania and sleep, In: Selected Writings of $\sigma$ Bertram D. Lewin (Ed. by J. Arlow). Psychoanalytic Quarterly Inc., New York.

LEWIN, B. (1955) Dream psychology and the analytic situation. In: Selected Writings of Bertram D. Lewin (Ed. by J.Arlow). Psychoanalytic Quarterly Inc., New York. MEISSNER, W.W. (1968) Dreaming as a process. International $\overrightarrow{0}$ Journal of Psychoanalysis, 49, 1, 63. 
Proceedings (1942) Symposium on neurotic disturbances of sleep. International Journal of Psychoanalysis, 23.

Scotr, C. (1952) Patients who sleep or look at the psychoanalyst during sessions. Technical considerations. International Journal of Psychoanalysis, 33, 465.

Silber, A. (1970) Functional phenomenon. Historical concept, contemporary defence. Journal of the American Psychoanalytical Association, 18, 519.
Stone, L. (1947) Transference sleep in a neurosis with duodenal ulcer. International Journal of Psychoanalysis, 28, 18.

Zetzel, E. (1970) Is the domain of the psychological still floating? International Psychiatry Clinics, 7, 2. 